\title{
Inadequate Diagnostic Evaluation in Young Patients Registered with a Diagnosis of Dementia: A Nationwide Register-Based Study
}

\author{
Lise Cronberg Salem $^{a} \quad$ Birgitte Bo Andersen $^{a} \quad$ T. Rune Nielsen ${ }^{a}$ \\ Jette Stokholm ${ }^{a}$ Martin Balslev Jørgensen ${ }^{b}$ Gunhild Waldemar ${ }^{a}$ \\ a Memory Disorders Research Group, Danish Dementia Research Centre, Department \\ of Neurology, Copenhagen University Hospital, Rigshospitalet, and b Psychiatric Centre \\ Copenhagen, Copenhagen University Hospital, Copenhagen, Denmark
}

\section{Key Words}

Diagnosis of dementia · Young patients - Quality of diagnostic work-up

\begin{abstract}
Background: Establishing a diagnosis of dementia in young patients may be complex and have significant implications for the patient. The aim of this study was to evaluate the quality of the diagnostic work-up in young patients diagnosed with dementia in the clinical routine. Methods: Two hundred patients were randomly selected from 891 patients aged $\leq 65$ years registered with a diagnosis of dementia for the first time in 2008 in Danish hospitals, and 159 medical records were available for review. Three raters evaluated their medical records for the completeness of the diagnostic work-up on which the diagnosis of dementia had been based, using evidence-based guidelines for the diagnostic evaluation of dementia as reference standards. Results: According to the rater review, only 111 (70\%) patients met the clinical criteria for dementia. An acceptable diagnostic work-up including all items of recommended basic diagnostic evaluation was performed in only $24 \%$, although more often (28\%) in the subgroup of patients where dementia was confirmed by raters. Conclusion: This first nationwide study of unselected young patients registered with a diagnosis of dementia indicated that the concept of dementia may be misinterpreted by clinicians and that a diagnosis of dementia in the young is only rarely based on a complete basic diagnostic work-up, calling for increased competency.

(c) 2014 S. Karger AG, Basel
\end{abstract}


Salem et al.: Inadequate Diagnostic Evaluation in Young Patients Registered with a

Diagnosis of Dementia: A Nationwide Register-Based Study

\section{Introduction}

Diagnosing early-onset dementia may be more challenging than late-onset dementia due to the lower prevalence, the wider range of aetiologies and the more atypical clinical presentation. The prevalence of early-onset dementia is not known, but is estimated to be approximately 55:100,000 for patients aged 30-65 years [1, 2].

The lower risk of dementia in the young may lead to a delay in diagnosis as caregivers and physicians may be less likely to consider the possibility of a dementia disorder [3]. Furthermore, the causes of cognitive symptoms in young patients differ from those in elderly patients as psychiatric, metabolic and hereditary conditions are more frequent in young patients [4]. The phenotypic presentation of a chronic progressive dementia disorder may differ compared to elderly patients. For example, young patients with Alzheimer's disease (AD) may present with a constellation of impairment in several cognitive domains, e.g. language, calculation, perception, spatial and constructional skills, rather than isolated memory impairment [5-7].

The diagnostic challenges may extend the time from onset of symptoms to diagnosis in young patients with dementia disorders or lead to a misdiagnosis of dementia in patients with other conditions. In patients with a dementia disorder, the timely diagnosis of dementia is a prerequisite for the initiation of adequate treatment, planning for the future and coping with the prognosis [3], and it is crucial that the diagnosis is valid and based on appropriate diagnostic evaluation according to national and international clinical guidelines.

To our knowledge, the quality of the diagnostic evaluation of dementia in young patients aged $\leq 65$ years has not been examined. We have previously used the Danish national registers to examine the adherence to international diagnostic guidelines for the diagnostic evaluation of dementia in the secondary health care sector. We found that satisfactory or acceptable completion of a basic dementia work-up was available in only $51 \%$ of elderly patients diagnosed and registered with dementia [8].

Furthermore, the Danish national registers were used to examine the validity of dementia diagnoses in a population of patients aged $\leq 65$ years registered with a diagnosis of dementia in 2008 [9]. Taken together, our results suggest that dementia is overdiagnosed and overregistered in young patients. To further elaborate these findings, we wished to evaluate the content and quality of the diagnostic work-up in this population of younger patients who had been registered with a diagnosis of dementia as part of the clinical routine in the secondary health care sector.

\section{Materials and Methods}

\section{The Danish Hospital Registers}

The Danish Civil Registration System assigns unique national identification numbers to all Danish residents and records individual demographic data such as age, gender, birthplace, residence, marital status, citizenship, kinship, emigration, and death (www.cpr.dk). Using these identification numbers each individual's contact with the secondary health care system is registered in two national hospital registers. Since 1969, all psychiatric contacts have been recorded in the Psychiatric Central Research Register (PCRR), while all somatic contacts have been recorded in the National Patient Register (NPR) since 1977. From 1995 onwards, both registers also encompassed data from hospital-based outpatient clinics and emergency departments. From 2002 onwards, the Danish hospital registers also included data from private specialist clinics and hospitals [10]. Submission of data to both registers is obligatory and electronic. In both registers, diagnoses are registered by use of the Inter- 
Salem et al.: Inadequate Diagnostic Evaluation in Young Patients Registered with a

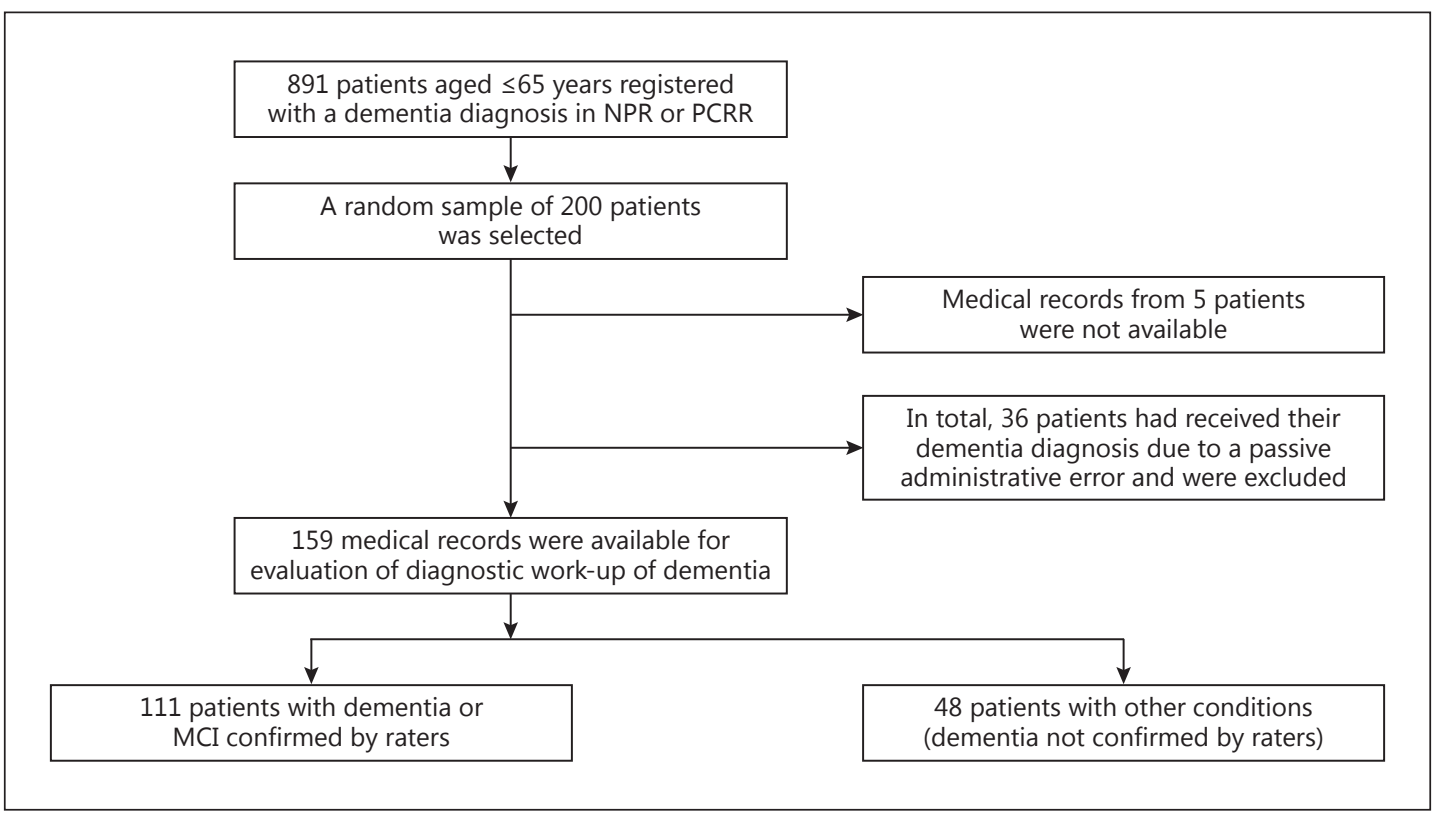

Fig. 1. Flow chart for the study population.

national Classification Disease (ICD) codes, classified by the World Health Organization. From 1994 onwards, ICD-10 replaced ICD-8, and ICD-10 still is the applied standard classification system [11].

\section{Study Population}

By linking the PCRR with the NPR, we obtained a study population of all patients registered for the first time with a diagnosis of dementia as a primary or secondary diagnosis in 2008 (January 1st to December 31st). This population included both in- and outpatients from public hospitals of all regions of Denmark. ICD-10 codes were used to identify the relevant diagnoses of AD (F00.0-9 and G30.0-9), vascular dementia (VaD) (F01.0-9), frontotemporal dementia (FTD) (F02.0), dementia with Lewy bodies (DLB) (G31.8 and F00.2) and unspecified dementia (F03.9). From a total of 891 patients, a random sample of 200 aged $\leq 65$ years at the index contact was selected for further evaluation via the random number generator from the SAS statistical package (v. 9.1.3) (fig. 1). In case patients were registered with a diagnosis of dementia more than once during 2008, only the first contact was included as the index contact. The index contact was defined as the contact at which a dementia diagnosis was registered for the first time.

The patients were classified according to the medical specialty of the department at the index contact: neurology, psychiatry, geriatrics, internal medicine (including all subspecialties), surgery (including all subspecialties) and other specialties. These departments were further classified into two groups: departments with dementia specialists and departments with other specialists. Departments with dementia specialists were defined as departments with specialists with special interest and competence in dementia (psychiatry, geriatrics, and neurology).

This report does not include patients who have been registered with a dementia diagnosis due to a passive administrative error. 
Salem et al.: Inadequate Diagnostic Evaluation in Young Patients Registered with a

Diagnosis of Dementia: A Nationwide Register-Based Study

\section{Evaluation Process}

Letters were sent to all relevant hospital departments to request a copy of the 200 medical records.

Step 1: Evaluating the Clinical Dementia Diagnoses

The validity of the dementia diagnosis in our 200 randomly selected patients from the hospital registers was evaluated in a previous publication [9]. Briefly, guided by the quality of clinical information about the diagnostic work-up in the medical records it was determined whether dementia and dementia subtypes could be confirmed according to diagnostic criteria $[9,12-15]$.

The clinical dementia diagnoses documented in the medical records were compared to the corresponding rater diagnoses obtained by the validating process. The clinical diagnosis was defined as the diagnosis mentioned by the local clinician in the medical records. The rater diagnosis was defined as the consensus diagnosis reached by the raters by using information available in the medical records and current diagnostic criteria.

Step 2: Evaluating the Diagnostic Work-Up

The quality of the diagnostic evaluation of dementia in the secondary health care sector was validated based on the clinical information in the patients' medical records and generally accepted clinical guidelines for the diagnostic evaluation of dementia available in 2008 [16]. Based on these guidelines, a complete basic work-up for dementia should contain as a minimum: history of cognitive symptoms, cognitive testing, psychiatric evaluation, physical examination including neurological examination, assessment of activities of daily living (ADL), a battery of blood tests, ECG and CT or MRI scan of the brain [16].

Three raters - a consulting neurologist (B.B.A.), a neuropsychologist (J.S.) and a consulting psychiatrist (M.B.J.) - independently reviewed and rated the medical records. Each rater was blinded in relation to the rating results from the other raters. The results of the rating process were compared and any disagreement was clarified at consensus meetings.

The quality of documentation for each item of the basic dementia work-up was rated according to 4 categories: (1) well-documented, (2) sufficiently documented, (3) insufficiently documented and (4) not documented. Only the items rated as categories 1 and 2 were considered as valid clinical information. A guide was provided to the raters, as shown in table 1. For further information, see our previous publication on the cohorts of elderly patients [17].

Regarding information on cognitive testing, physical examination, neurological examination, psychiatric evaluation and neuroimaging, a written summary of positive findings was accepted as valid clinical information. The information on the results of blood tests was inconsistent as in some hospital departments, laboratory testing had been stored in alternative electronic systems and not made available for our review. Therefore, the ratings on the availability of blood test results were not included in the present study.

Clinical information and results of investigations performed at previous health care contacts within predefined time limits were used to supplement information obtained at the index contact where dementia was registered for the first time. The rating procedure and the rationale behind the adopted time limits have been described in detail elsewhere [17].

To be considered as an acceptable basic dementia work-up, all items of the work-up had to be rated as 'valid clinical information', or if any information about cognitive testing, evaluation of mental status, physical examination or neurological examination was missing, the available clinical information had to leave no doubt that the patient fulfilled DSM-IV or ICD-10 criteria for dementia $[12,18]$. 
Salem et al.: Inadequate Diagnostic Evaluation in Young Patients Registered with a

Diagnosis of Dementia: A Nationwide Register-Based Study

Table 1. Categories to rate each item of the dementia work-up

\begin{tabular}{|c|c|c|c|c|c|}
\hline \multirow[t]{2}{*}{ Work-up } & \multicolumn{4}{|l|}{ Categories } & \multirow{2}{*}{$\begin{array}{l}\text { Time limit for } \\
\text { information prior to the } \\
\text { contact when dementia } \\
\text { was diagnosed }\end{array}$} \\
\hline & (1) well-documented & $\begin{array}{l}\text { (2) sufficiently } \\
\text { documented }\end{array}$ & (3) insufficiently documented & $\begin{array}{l}\text { (4) not } \\
\text { documented }\end{array}$ & \\
\hline $\begin{array}{l}\text { History of } \\
\text { cognitive } \\
\text { symptoms }\end{array}$ & $\begin{array}{l}\text { Detailed history } \\
\text { including onset, } \\
\text { progression, cognitive } \\
\text { symptoms and } \\
\text { functional impairment }\end{array}$ & $\begin{array}{l}\text { Sufficient history to } \\
\text { document progressive } \\
\text { cognitive impairment } \\
\text { and functional loss }\end{array}$ & $\begin{array}{l}\text { Dementia or cognitive } \\
\text { symptoms noted in the } \\
\text { medical journals without } \\
\text { further elaboration }\end{array}$ & $\begin{array}{l}\text { No } \\
\text { information }\end{array}$ & None \\
\hline $\begin{array}{l}\text { Cognitive } \\
\text { test }\end{array}$ & $\begin{array}{l}\text { Results from standard } \\
\text { tests or evaluation by } \\
\text { a neuropsychologist }\end{array}$ & $\begin{array}{l}\text { A physician } \\
\text { summarized the } \\
\text { positive findings from } \\
\text { the tests }\end{array}$ & $\begin{array}{l}\text { Documented as being } \\
\text { done, but the findings } \\
\text { were not available for } \\
\text { review }\end{array}$ & $\begin{array}{l}\text { No } \\
\text { information }\end{array}$ & $\begin{array}{l}\text { None if standard test } \\
\text { was abnormal, } \\
\text { otherwise within } 6 \\
\text { months }\end{array}$ \\
\hline $\begin{array}{l}\text { Psychiatric } \\
\text { evaluation }\end{array}$ & $\begin{array}{l}\text { A full mental status } \\
\text { documented }\end{array}$ & $\begin{array}{l}\text { A physician } \\
\text { summarized the } \\
\text { abnormal findings }\end{array}$ & $\begin{array}{l}\text { Scarcely documented, } \\
\text { insufficient to rule out } \\
\text { psychiatric illness such } \\
\text { as depression }\end{array}$ & $\begin{array}{l}\text { No } \\
\text { information }\end{array}$ & $\begin{array}{l}\text { Had to be done at } \\
\text { the contact when } \\
\text { dementia was } \\
\text { diagnosed }\end{array}$ \\
\hline $\begin{array}{l}\text { Physical } \\
\text { examination }\end{array}$ & $\begin{array}{l}\text { A full physical } \\
\text { examination } \\
\text { documented }\end{array}$ & $\begin{array}{l}\text { A physician } \\
\text { summarized the } \\
\text { abnormal findings }\end{array}$ & $\begin{array}{l}\text { Scarcely documented, } \\
\text { insufficient to rule out } \\
\text { systemic causes of } \\
\text { cognitive impairment }\end{array}$ & $\begin{array}{l}\text { No } \\
\text { information }\end{array}$ & Within 6 months \\
\hline $\begin{array}{l}\text { Neurological } \\
\text { examination }\end{array}$ & $\begin{array}{l}\text { A full neurological } \\
\text { examination } \\
\text { documented }\end{array}$ & $\begin{array}{l}\text { A physician } \\
\text { summarized the } \\
\text { abnormal findings }\end{array}$ & $\begin{array}{l}\text { Scarcely documented, } \\
\text { insufficient to help } \\
\text { determine the } \\
\text { neurological condition } \\
\text { underlying dementia }\end{array}$ & $\begin{array}{l}\text { No } \\
\text { information }\end{array}$ & Within 6 months \\
\hline $\begin{array}{l}\text { Neuroimaging } \\
\text { (CT, MRI) }\end{array}$ & $\begin{array}{l}\text { Radiological images or } \\
\text { formal report by a } \\
\text { radiologist }\end{array}$ & $\begin{array}{l}\text { A physician } \\
\text { summarized the } \\
\text { abnormal findings }\end{array}$ & $\begin{array}{l}\text { Documented as being } \\
\text { done, but the findings } \\
\text { were not documented }\end{array}$ & $\begin{array}{l}\text { No } \\
\text { information }\end{array}$ & Within 1 year \\
\hline Blood tests & $\begin{array}{l}\text { Full panel of blood } \\
\text { tests done with results } \\
\text { documented }\end{array}$ & $\begin{array}{l}\text { Up to } 2 \text { blood tests } \\
\text { could be missing, but } \\
\text { complete blood count, } \\
\text { glucose, creatinine } \\
\text { and TSH had to be } \\
\text { documented }\end{array}$ & $\begin{array}{l}\text { Scarcely documented, } \\
\text { insufficient to rule out } \\
\text { systemic causes to } \\
\text { cognitive impairment }\end{array}$ & $\begin{array}{l}\text { No } \\
\text { information }\end{array}$ & Within 6 months \\
\hline ADL & $\begin{array}{l}\text { Documented by } \\
\text { formal interview such } \\
\text { as instrumental ADL }\end{array}$ & $\begin{array}{l}\text { Description of reduced } \\
\text { ADL but no formal } \\
\text { rating }\end{array}$ & $\begin{array}{l}\text { Scarcely documented, } \\
\text { insufficient to prove that } \\
\text { there was decline in } \\
\text { function }\end{array}$ & $\begin{array}{l}\text { No } \\
\text { information }\end{array}$ & None \\
\hline
\end{tabular}

\section{Comparison with Data for Elderly Patients}

The presence of valid clinical information for each item of the basic dementia work-up for the young population was compared with the corresponding results from a previous study in elderly patients [17]. Overall, the previous study in elderly patients was based on the review of medical records of 197 patients with a diagnosis of dementia established in 2003. The mean age at the time of the diagnosis was $81(\mathrm{SD}=9)$.

The research project was approved by the Danish Data Protection Agency and the National Board of Health. 
Salem et al.: Inadequate Diagnostic Evaluation in Young Patients Registered with a Diagnosis of Dementia: A Nationwide Register-Based Study

Table 2. Patient characteristics and medical history (at index contact)

\begin{tabular}{lcc}
\hline & Number & Percent \\
\hline Patient characteristics & & \\
Patients & 159 & \\
Age ${ }^{2}$, years & $59.1(27-65)$ & \\
Sex ratio (M:F) & $86: 73$ & $54: 46$ \\
Active on labour market & 11 & 7 \\
Disability pension & 94 & 60 \\
Children living at home & 5 & 3 \\
\hline Medical history & & \\
Family history of dementia & 11 & 7 \\
Head trauma & 8 & 5 \\
Down's syndrome & 12 & 8 \\
Metabolic disorder & 14 & 9 \\
Cardiovascular disease & 23 & 15 \\
Hypertension & 23 & 15 \\
Diabetes mellitus & 14 & 9 \\
Hypercholesterolaemia & 16 & 10 \\
Depression & 73 & 46 \\
Current alcohol abuse & 34 & 21 \\
Previous alcohol abuse & 58 & 37 \\
\hline Type of index contact & & \\
Outpatients & 91 & 57 \\
Inpatients (acute admission) & 62 & 39 \\
Inpatients (elective admission) & 6 & 4 \\
\hline Medical specialty at index contact & & \\
Psychiatry & 71 & 45 \\
Geriatrics & 9 & 6 \\
Neurology & 49 & 31 \\
Internal medicine & 7 & 4 \\
Surgery & 6 & \\
Other specialties & & \\
\hline & & \\
\hline
\end{tabular}

${ }^{\text {a }}$ Mean age with range in parentheses.

\section{Statistical Analyses}

Data analysis was done with the SPSS statistical package (version 19.0 for Windows, SPSS Inc., Chicago, Ill., USA).

Fisher's exact test was used to compare differences in the diagnostic work-up of dementia and in the application of supplementary diagnostic tools between specialties, and ANOVA was applied to compare differences between young patients with and without a dementia diagnosis confirmed by raters and elderly patients concerning the presence of valid clinical information for each item of the evidence-based basic dementia work-up. Post hoc comparisons were used to find out which groups were significantly different from one another.

\section{Results}

\section{Background Information}

Medical records from 159 (82\%) patients, 86 (54\%) males, were available for the evaluation of the diagnostic work-up; however, 5 patients had no available medical records. Thirtysix patients had been registered with a dementia diagnosis due to a passive administrative 
Table 3. Clinical diagnosis from medical record, as compared to rater diagnosis

\begin{tabular}{|c|c|c|c|c|c|c|c|c|}
\hline & \multicolumn{8}{|c|}{ Rater diagnosis } \\
\hline & $\begin{array}{l}\mathrm{AD} \text { and } \\
\text { mixed }\end{array}$ & $\mathrm{VaD}$ & FTD & $\begin{array}{l}\text { unspecified } \\
\text { dementia }\end{array}$ & $\begin{array}{l}\text { other } \\
\text { dementia }\end{array}$ & $\begin{array}{l}\text { dementia } \\
\text { ruled out }\end{array}$ & $\begin{array}{l}\text { unable to } \\
\text { conclude }\end{array}$ & total \\
\hline \multicolumn{9}{|l|}{ Clinical diagnosis } \\
\hline $\mathrm{AD}$, mixed $\mathrm{AD} / \mathrm{VaD}$ & 42 & 0 & 0 & 1 & 0 & 0 & 4 & 47 \\
\hline $\mathrm{VaD}$ & 2 & 16 & 0 & 1 & 1 & 0 & 2 & 22 \\
\hline DLB & 0 & 0 & 0 & 0 & 0 & 0 & 1 & 1 \\
\hline FTD & 0 & 2 & 3 & 1 & 0 & 0 & 1 & 7 \\
\hline Alcohol-related dementia & 2 & 1 & 0 & 2 & 4 & 1 & 5 & 15 \\
\hline Unspecified dementia & 0 & 5 & 2 & 13 & 10 & 1 & 32 & 64 \\
\hline Other dementia & 0 & 0 & 0 & 0 & 2 & 0 & 1 & 3 \\
\hline Total & 46 & 25 & 5 & 18 & 17 & 2 & 46 & 159 \\
\hline Dementia or MCI present & & & & & & & & 111 \\
\hline
\end{tabular}

Figures in bold indicate full agreement.

error, and their medical records were excluded from further evaluation in this report (fig. 1). The medical records of these patients did not contain any information about possible dementia symptoms, and it was assumed that they had been registered with a dementia diagnosis due to an error. The mean age of the patients at the 1st index contact was 59.1 (range 27-65) years, with $41 \%$ under the age of 60 years.

The patients had been registered with a dementia diagnosis in 41 different public hospitals, covering all regions of Denmark. For the distribution of the registered dementia diagnoses, see our previous paper [9].

At the time of the index contact, $60 \%$ of the patients received disability pension, $7 \%$ were active on the labour market and $6 \%$ were on sick leave. The remaining patients were either applying for disability pension or the information on the occupational status was not available in the medical records.

Altogether, $129(82 \%)$ of the 159 patients were seen by dementia specialists (neurology, geriatrics and psychiatry) at the index contact. Ninety-one patients (57\%) were outpatients, of whom dementia specialists had diagnosed 98\%. Another 62 patients (39\%) were registered following acute admission, but only $58 \%$ of these patients had been diagnosed by dementia specialists (table 2).

The majority (58\%) of the patients receiving a diagnosis during acute admission were diagnosed with unspecified dementia. Only $10(16 \%)$ of the patients diagnosed during acute admission were subsequently referred to a memory clinic or specialist department for followup. For further information on demographics and medical history, see table 2 .

\section{Clinical Diagnoses}

The clinical diagnoses listed in the medical records were: unspecified dementia (40\%), $\mathrm{AD}$ and mixed $\mathrm{AD} / \mathrm{VaD}(30 \%), \mathrm{VaD}(14 \%)$, DLB (1\%), FTD (4\%), alcohol-related dementia (9\%) and other dementia (2\%).

The raters confirmed the clinical diagnosis of dementia in $111(70 \%)$ of the 159 patients (fig. 1); 42 with a clinical diagnosis of $\mathrm{AD}, 16$ with a clinical diagnosis of $\mathrm{VaD}, 3$ with a clinical diagnosis of FTD and 13 with a clinical diagnosis of unspecified dementia (table 3).

In total, 48 patients did not meet the diagnostic criteria for dementia according to the raters. For some of these patients, the raters suggested other possible contributing factors 
Salem et al.: Inadequate Diagnostic Evaluation in Young Patients Registered with a

Diagnosis of Dementia: A Nationwide Register-Based Study

Table 4. Availability of diagnostic work-up in patients diagnosed with dementia

\begin{tabular}{|c|c|c|c|c|c|c|}
\hline & \multicolumn{6}{|c|}{ Specialties, \% } \\
\hline & $\begin{array}{l}\text { psychiatry } \\
(\mathrm{n}=71)\end{array}$ & $\begin{array}{l}\text { geriatric } \\
(\mathrm{n}=9)\end{array}$ & $\begin{array}{l}\text { neurology } \\
(n=49)\end{array}$ & $\begin{array}{l}\text { internal } \\
\text { medicine } \\
(\mathrm{n}=16)\end{array}$ & $\begin{array}{l}\text { surgery } \\
(n=6)\end{array}$ & $\begin{array}{l}\text { other } \\
(n=7)\end{array}$ \\
\hline
\end{tabular}

Basic diagnostic work-up

History of cognitive symptoms

Cognitive test (any)

Psychiatric evaluation

Physical examination

Neurological examination

Neuroimaging

ADL

$\begin{array}{rrrr}104(65) & 69 & 89 & 88 \\ 97(61) & 62 & 78 & 82 \\ 17(74) & 90 & 67 & 74 \\ 97(61) & 34 & 78 & 80 \\ 90(57) & 32 & 78 & 96 \\ 10(69) & 56 & 78 & 96 \\ 22(77) & 70 & 100 & 88 \\ 38(24) & 11 & 56 & 47\end{array}$

$88-12$

$12 \quad 14 \quad 17 \quad<0.001$

All items available

$38(24) \quad 11$

82

74

80

96

96

88

Supplementary diagnostic work-up

Neuropsychological examination

MRI

CSF examination

SPECT-CBF scan

$32(20)$

$32(20)$

$14(9)$

FDG-PET scan

Genetic testing

7 (4)

5 (3)

EEG

$11(7)$

DAT scan

1 (1)

$\begin{array}{rrrlllr}25 & 56 & 41 & 1 & 0 & 0 & 0.004 \\ 14 & 22 & 41 & 0 & 0 & 0 & 0.001 \\ 9 & 22 & 49 & 0 & 0 & 0 & <0.001 \\ 4 & 11 & 20 & 0 & 0 & 0 & 0.041 \\ 1 & 0 & 12 & 0 & 0 & 0 & 0.142 \\ 1 & 0 & 8 & 0 & 0 & 0 & 0.424 \\ 6 & 0 & 14 & 0 & 0 & 0 & 0.385 \\ 1 & 0 & 0 & 0 & 0 & 0 & 1.0\end{array}$

Valid clinical information was defined as categories 1 and 2. The specialties indicate the type of department where the patients received a dementia diagnosis for the first time. The level of significance was based on Fisher's exact test. CBF $=\mathrm{Cerebral}$ blood flow; DAT = dopamine transporter; PET = positron emission tomography; FDG = fluorodeoxyglucose.

leading to cognitive symptoms. In $35 \%$ of these patients, the cognitive symptoms might have been caused by other specific brain diseases, in $31 \%$ by a psychiatric disorder, in $32 \%$ by drug and/or alcohol abuse, in $13 \%$ by other somatic diseases and in $1 \%$ the diagnosis of dementia might have been given in order to provide the possibility for the patient to get disability pension or other social support. In 3\%, no obvious cause was evident.

\section{Quality of Diagnostic Evaluation in Young Patients}

A satisfactory or acceptable diagnostic work-up including all items in the basic dementia work-up had been done in only 38 (24\%) patients, of whom 24 (63\%) were outpatients. Most of these patients were diagnosed by dementia specialists (table 4). In total, 104 (65\%) patients had valid information in the medical records regarding history of cognitive symptoms, 97 (61\%) had valid information on cognitive tests, 117 (74\%) had valid information on psychiatric examination, 90 (57\%) on neurological examination, 110 (69\%) on neuroimaging and $122(77 \%)$ had valid information on ADL. Fisher's exact test showed significant differences $(p<0.005)$ between specialties in all items except for information regarding ADL $(p=0.065)$. Overall, the fulfilment of the criteria of each item of the diagnostic work-up was low, but highest when it was performed by dementia specialists and in patients where dementia was confirmed by raters (tables 4,5 ).

The application of supplementary diagnostic tools [neuropsychological examination, MRI, cerebrospinal fluid (CSF) examination including AD markers in CSF, cerebral blood flow measured by single photon emission computed tomography (SPECT), fluorodeoxyglucose positron emission tomography, genetic testing, EEG and dopamine transporter SPECT imaging] in the diagnostic work-up of dementia is shown in table 4 . The supplementary tools 
Table 5. Quality of diagnostic work-up in young patients with and without dementia according to raters compared to patients from the elderly population

\begin{tabular}{l|l}
\hline \multicolumn{2}{l|}{ Dement Geriatr Cogn Disord Extra 2014;4:31-44 } \\
\hline DOI: $10.1159 / 000358050$ & $\begin{array}{l}\text { C 2014 S. Karger AG, Basel } \\
\text { www.karger.com/dee }\end{array}$ \\
\hline
\end{tabular}

Salem et al.: Inadequate Diagnostic Evaluation in Young Patients Registered with a Diagnosis of Dementia: A Nationwide Register-Based Study

\begin{tabular}{|c|c|c|c|c|}
\hline \multirow[t]{2}{*}{ Diagnostic work-up } & \multicolumn{3}{|l|}{ Patient group } & \multirow[t]{2}{*}{$\mathrm{p}$ value } \\
\hline & $\begin{array}{l}\text { young patients, } \\
\text { dementia } \\
\text { confirmed by } \\
\text { raters, } \%(n=111)\end{array}$ & $\begin{array}{l}\text { young patients, } \\
\text { dementia not } \\
\text { confirmed by } \\
\text { raters, } \%(n=48)\end{array}$ & $\begin{array}{l}\text { elderly } \\
\text { patients, } \\
\%(n=197)\end{array}$ & \\
\hline \multicolumn{5}{|l|}{ History of cognitive } \\
\hline Cognitive test & 68 & $46^{a, b}$ & 62 & 0.029 \\
\hline Psychiatric evaluation & $80^{\mathrm{a}}$ & $58^{\mathrm{b}}$ & 64 & 0.004 \\
\hline Physical examination & 56 & 73 & 66 & 0.093 \\
\hline Neurological examination & 62 & 44 & 53 & $0.068^{c}$ \\
\hline Neuroimaging (CT or MRI) & 74 & 58 & 73 & 0.092 \\
\hline ADL & $83^{\mathrm{a}}$ & $63^{\mathrm{b}}$ & 79 & 0.014 \\
\hline All items available & $28^{\mathrm{a}}$ & $15^{\mathrm{a}}$ & 53 & $<0.001$ \\
\hline
\end{tabular}

Valid clinical information was defined as categories 1 and 2. Data on patients from the general population were obtained from Phung et al. [17]. Level of significance between patient groups based on the Kruskal-Wallis tests.

${ }^{a}$ Post hoc comparisons using the Tukey HSD test indicated that the mean score differed significantly from elderly patients. ${ }^{\mathrm{b}}$ Post hoc comparisons using the Tukey HSD test indicated that the mean score differed significantly from young patients, dementia confirmed. ${ }^{c}$ Level of significance was based on ANOVA.

were primarily applied by dementia specialists. We found a significant difference between dementia specialties regarding the use of neuropsychological examination $\left[\chi^{2}(2, n=159)=\right.$ 11.532, $\mathrm{p}=0.004]$, use of MRI $\left[\chi^{2}(2, \mathrm{n}=159)=13.805, \mathrm{p}<0.001\right]$ and examination of CSF $\left[\chi^{2}(2, n=159)=24.794, p<0.001\right]$. Overall, neurologists applied these supplementary diagnostic tools most often.

Of the young patients registered with a diagnosis of $\mathrm{AD}, 37 \%$ had been examined by a neuropsychologist, $22 \%$ had an MRI and 37\% underwent a CSF examination.

\section{Comparison with Data for Elderly Patients}

The quality of the diagnostic evaluation performed by dementia specialists in elderly patients compared to young patients with and without dementia according to raters is summarized in table 5. The ANOVA test used as a parametric test and the Kruskal-Wallis test used as a non-parametric test showed significant differences $(p<0.05)$ between the three samples, regarding the validity of clinical information on history of cognitive symptoms, cognitive test, psychiatric evaluation, ADL and all items.

\section{Discussion}

To our knowledge, this is the first study to evaluate the diagnostic work-up of dementia as conducted in the routine clinical setting in young patients registered with a diagnosis of dementia. There were three important findings: first, only $70 \%$ of young patients diagnosed with dementia (55\% of those registered with dementia) met the diagnostic criteria for dementia; second, an adequate basic diagnostic work-up was conducted in only a minority $(24 \%)$ of patients and supplementary diagnostic investigations were only rarely applied, and third, the likelihood of an adequate and complete diagnostic evaluation was, as expected, higher when performed by dementia specialists.

The aim of the diagnostic evaluation programme is to clarify the underlying cause of cognitive impairment in order to offer specific treatment if available and early psychosocial 
Salem et al.: Inadequate Diagnostic Evaluation in Young Patients Registered with a

Diagnosis of Dementia: A Nationwide Register-Based Study

support for patients with dementia disorders. Furthermore, the evaluation aims to identify potentially reversible causes of cognitive impairment and patients who do not have a chronic progressive dementia disorder. According to evidence-based guidelines, the basic diagnostic evaluation of patients with cognitive impairment should include the following minimum set of investigations: history of cognitive symptoms, cognitive testing, psychiatric evaluation, physical examination, neurological examination, assessment of ADL, routine laboratory blood tests, ECG and CT or MRI of the brain $[16,19]$. Furthermore, supplementary investigations (neuropsychological examination, CSF examination including AD markers in CSF, cerebral blood flow measured by SPECT, fluorodeoxyglucose positron emission tomography, genetic testing, EEG and dopamine transporter SPECT imaging) may be applied in selected cases in order to identify the underlying disorder $[16,19]$.

Overall, only $24 \%$ of the patients in our study had valid clinical information in their medical records on all items of the basic dementia work-up. Surprisingly, this percentage was significantly lower as compared to our previous study in elderly patients in which a valid diagnostic work-up containing all items of the recommended evidence-based basic diagnostic work-up had been performed in 53\% of the patients [17]. However, valid clinical information in the medical records on the diagnostic work-up was identified more often in young patients where the diagnosis of dementia was confirmed by our raters $(28 \%)$ as compared to young patients in whom dementia was not confirmed by raters (15\%) (table 3).

Valid information was obtained on the history of cognitive symptoms and ADL in 65 and $77 \%$, respectively. The clinical history is important in the diagnostic process and should include the cognitive domains affected, the mode of onset, the pattern of progression and the impact on ADL. Also, past medical history, current comorbidities, family history and educational history are important, and it is recommended that the clinical history should be supplemented by an independent informant where available [16, 20]. In more than one third of our study population, the information on medical history was inadequate, which could lead to a more limited diagnostic work-up and thereby increase the risk of misdiagnosis.

Assessment of cognitive function is important as the diagnosis of dementia must be based on evidence of cognitive deficits. Consequently, it is recommended that cognitive testing should be performed in all patients during the diagnostic process [16, 20]. Nonetheless, only $61 \%$ of our study population had valid information in medical records regarding cognitive tests.

Psychiatric evaluation is essential in order to assess behavioural and psychological symptoms and should be performed in all patients, since these symptoms are common and contribute to patient distress and caregiver burden [16, 20]. Psychiatric evaluation is also of significant value in identifying patients in whom a dementia disorder may not be the cause of cognitive symptoms. Neuropsychiatric symptoms were assessed acceptably in $74 \%$ of our study population.

In order to identify neurodegenerative disorders associated with specific neurological or other physical signs and to identify other somatic conditions causing cognitive impairment, a general physical and neurological examination should be performed on all patients presenting with dementia $[16,20]$. In our study, according to the medical records, this was done in only $61 \%$ of all patients.

Structural neuroimaging should be performed in all cases of suspected dementia. According to the international guidelines available in 2008, non-contrast CT is sufficient, but if available, MRI is preferred and may be used to show specific abnormalities [16, 20]. Accordingly, all our patients should have had a CT or MRI scan of the brain, but this was done in only $69 \%$ of our study population.

It is recommended for all patients at first evaluation to have the following blood test screening $[16,20]$ : blood sedimentation rate, complete blood cell count, electrolytes, calcium, 
Salem et al.: Inadequate Diagnostic Evaluation in Young Patients Registered with a

Diagnosis of Dementia: A Nationwide Register-Based Study

glucose, renal and liver function tests, and TSH. In this study, we were not able to assess the completeness of blood test screening, but we would expect blood tests to be done routinely in clinical practice as was the case for $83 \%$ of our elderly population [17].

Only one third of our study population had a neuropsychological assessment. According to Smits et al. [7], memory is often preserved in young patients with $\mathrm{AD}$, particularly in the mild stages, stressing the need to adequately assess other cognitive domains in the neuropsychological assessment to avoid misdiagnosis. Furthermore, neuropsychological examination is often helpful in identifying patients who do not have a dementia disorder as the underlying cause of cognitive symptoms.

CSF analysis with routine cell count, protein, glucose and protein electrophoresis is recommended in patients with a clinical suspicion of certain diseases and in patients with atypical clinical presentations [16, 20,21]. Furthermore, examination of AD markers in CSF is increasingly used to differentiate $\mathrm{AD}$ from other neurodegenerative dementias. In AD, CSF is usually acellular with a normal protein level and CSF tau (total levels and specific phosphorylated forms) is increased, while CSF A 342 is reduced [21]. Only 20\% of our study population had a CSF examination done during the diagnostic work-up (table 4).

We would expect supplementary diagnostic tools to be applied more frequently in young patients with cognitive symptoms as the phenotypic presentation of neurodegenerative disease and the profile of other underlying causes leading to cognitive symptoms may differ from those in elderly patients [4-6, 22]. In general, the investigations commonly undertaken in older patients with cognitive impairment also apply to young patients, but the more challenging differential diagnosis will often mandate a full investigation [4].

The remarkable inadequacy of the diagnostic evaluation may partly be explained by the fact that more than one third of the study population had been registered with a diagnosis of dementia during an acute admission. At an acute admission, patients may be cognitively impaired due to one or more coexisting conditions, e.g. infection, delirium, dehydration and fever. Therefore, a diagnosis of dementia should not be established during acute admission. Rather, patients with cognitive symptoms should be referred to a memory clinic for further diagnostic evaluation. The fact that young patients may be diagnosed and registered with a dementia diagnosis during acute admissions in various hospital departments has not previously been reported, as most studies on early-onset dementia are based on data obtained from memory clinics $[5,6,23-26]$. Overall, $81 \%$ of the patients were diagnosed by dementia specialists who, as expected, performed a more adequate diagnostic evaluation although still insufficient in many cases. These results are in accordance with our previous study on elderly patients [17].

Conditions causing cognitive impairment may be progressive, static or reversible, depending on the aetiology, e.g. neurodegenerative dementia disorders, traumatic brain injury, metabolic disorders, alcohol-related brain damage or psychiatric disorder. Approximately one third of our study population had previous and/or current alcohol abuse at the index contact, and 15 patients had a clinical diagnosis of alcohol-related dementia, which may contribute to the generally low rate of completion of the diagnostic evaluation in our cohort. Alcohol-related dementia is not a universally accepted concept and little is known about the role of alcohol use in causing permanent cognitive impairment [27]. Moreover, it has been demonstrated that abstinence from alcohol may lead to a marked improvement in cognitive deficits [28]. Diagnosing dementia in a patient with current alcohol abuse may be a token of the clinician's suspicion of cognitive impairment. However, it is questionable whether dementia can be diagnosed reliably in patients with active alcohol abuse following an acute admission.

An inadequate diagnostic work-up may result in overdiagnosis as well as under-diagnosis of dementia, and in patients with dementia inadequate investigations may lead to a wrong diagnosis and to insufficient treatment. Overdiagnosis of dementia may occur in 
Salem et al.: Inadequate Diagnostic Evaluation in Young Patients Registered with a

Diagnosis of Dementia: A Nationwide Register-Based Study

patients who exhibit subjective cognitive symptoms during an acute or elective admission to a hospital, which may lead the clinician to suspect dementia. This issue was described in our previous study, demonstrating that only $58 \%$ of dementia diagnoses in young patients registered in the Danish national hospital registers were correct [9]. Hence, the remaining $42 \%$ of the dementia diagnoses were found to be invalid by the raters. These cases probably reflect a range of conditions which may be misinterpreted as dementia [9]. In some patients, the subjective cognitive symptoms may be due to one or more from a wide range of conditions (e.g. depression, hepatic encephalopathy due to alcohol abuse and chronic psychiatric diseases) which may be misinterpreted as dementia. In the same population of young patients, we now demonstrate that in most cases one if not all items of the basic diagnostic work-up programme were inadequate. Particularly in patients registered with a dementia diagnosis without having a progressive dementia disorder, an adequate work-up had been useful in order to avoid stigmatization. Overall, it is important that the information on which a dementia diagnosis is based meets evidence-based minimum standards.

To which extent an insufficient diagnostic work-up may lead to an underdiagnosis of dementia in the young cannot be clarified in the present study which included only patients registered with a dementia diagnosis. A lack of an adequate diagnostic work-up may in some cases lead to underdiagnosis of dementia due to the failure to apply essential supplementary diagnostic evaluations when relevant.

Even in patients where the registered dementia diagnosis was confirmed by the raters, the diagnostic evaluation was very insufficient, and only complete in $28 \%$. Inadequate diagnostic work-up of dementia in patients with cognitive symptoms due to neurodegenerative disorder may lead to an unspecific or wrong diagnosis and a denial of the treatment and care they need for their specific dementia disorder.

There are a few methodological issues that should be taken into consideration to fully appreciate our results. First, this study is a nationwide register-based study making it possible to examine the diagnostic evaluation of dementia in a randomly selected population of young patients diagnosed in 'real life' clinical routine in hospital departments in 2008. Second, the three raters were dementia specialists in psychiatry, neurology and neuropsychology, respectively, which strengthened the independent rating process.

Our study also had important limitations. First, as information on the diagnostic evaluation was obtained from medical records, incomplete recording of available information could contribute to an underreporting of investigations performed in the basic dementia work-up. Therefore, the raters might conclude that the diagnostic work-up was insufficient, particularly in cases where the lack of information was due to underreporting. Second, this randomly selected population of young patients registered with a dementia diagnosis for the first time in the secondary health care sector included some patients with long-term subjective cognitive complaints, which were not the actual reason for referral. However, in any patient 'labelled' with a potentially stigmatizing diagnosis of dementia, the diagnosis should be clarified and confirmed (or rejected) based on an appropriate diagnostic work-up.

In conclusion, diagnostic evaluation of young patients diagnosed with dementia in the secondary health care sector did not meet the basic standards set by evidence-based clinical guidelines in the majority of patients, and many patients were not seen by dementia specialists. Furthermore, a large part of the patients were diagnosed during acute admission contributing to a massive overdiagnosis of dementia in young patients. However, the diagnostic evaluation was also inadequate in patients with a confirmed and validated diagnosis of dementia. Whether our results can be translated to the quality of diagnostic work-up in other countries is uncertain as no data are available. However, we anticipate that low performance in the often complex diagnostic evaluation of young patients with cognitive impairment may be an international issue. 
Salem et al.: Inadequate Diagnostic Evaluation in Young Patients Registered with a

Diagnosis of Dementia: A Nationwide Register-Based Study

There seems to be a significant gap between evidence-based diagnostic guidelines and 'real-world' diagnostic evaluation in young patients with cognitive or behavioural symptoms. Diagnostic evaluation of young patients may be complex and should be performed by specialists with experience in the field.

Our results call for a better focus on diagnostic challenges and the need for increased competency in diagnosing dementia in young patients in the future.

\section{Acknowledgements}

The authors would like to thank the Danish Research Foundation for a scholarship to L.C.S. and the Danish Health Foundation and the Danish Ministry of Health for support to the Danish Dementia Research Centre. The authors are grateful to the directors of all hospital departments involved in this study for willingly sending us copies of medical records.

\section{Disclosure Statement}

The authors have no actual or potential conflicts of interest related to the research in this paper.

\section{References}

$>1$ Harvey RJ, Skelton-Robinson M, Rossor MN: The prevalence and causes of dementia in people under the age of 65 years. J Neurol Neurosurg Psychiatry 2003;74:1206-1209.

-2 Borroni B, Alberici A, Grassi M, Rozzini L, Turla M, Zanetti O, Bianchetti A, Gilberti N, Bonvicini C, Volta GD, Rozzini R, Padovani A: Prevalence and demographic features of early-onset neurodegenerative dementia in Brescia County, Italy. Alzheimer Dis Assoc Disord 2011;25:341-344.

-3 van Vliet D, de Vugt ME, Bakker C, Pijnenburg YA, Vernooij-Dassen MJ, Koopmans RT, Verhey FR: Time to diagnosis in young-onset dementia as compared with late-onset dementia. Psychol Med 2012;1-10.

4 Rossor MN, Fox NC, Mummery CJ, Schott JM, Warren JD: The diagnosis of young-onset dementia. Lancet Neurol 2010;9:793-806.

5 Snowden JS, Thompson JC, Stopford CL, Richardson AM, Gerhard A, Neary D, Mann DM: The clinical diagnosis of early-onset dementias: diagnostic accuracy and clinicopathological relationships. Brain 2011;134:24782492.

-6 Koedam EL, Lauffer V, van der Vlies AE, van der Flier WM, Scheltens P, Pijnenburg YA: Early-versus late-onset Alzheimer's disease: more than age alone. J Alzheimers Dis 2010;19:1401-1408.

-7 Smits LL, Pijnenburg YA, Koedam EL, van der Vlies AE, Reuling IE, Koene T, Teunissen CE, Scheltens P, van der Flier WM: Early onset Alzheimer's disease is associated with a distinct neuropsychological profile. J Alzheimers Dis 2012;30:101-108.

-8 Phung TK, Andersen BB, Hogh P, Kessing LV, Mortensen PB, Waldemar G: Validity of dementia diagnoses in the Danish hospital registers. Dement Geriatr Cogn Disord 2007;24:220-228.

-9 Salem LC, Andersen BB, Nielsen TR, Stokholm J, Jorgensen MB, Rasmussen MH, Waldemar G: Overdiagnosis of dementia in young patients - A nationwide register-based study. Dement Geriatr Cogn Disord 2012;34:292299.

10 Lynge E, Sandegaard JL, Rebolj M: The Danish National Patient Register. Scand J Public Health 2011;39:30-33.

11 World Health Organization: The ICD-10 Classification of Mental and Behavioral Disorders: Diagnostic Criteria for Research. Geneva, World Health Organization, 2007.

12 American Psychiatric Association: Diagnostic and Statistical Manual of Mental Disorders. Washington, American Psychiatric Association, 2000.

13 McKeith IG, Dickson DW, Lowe J, Emre M, O’Brien JT, Feldman H, Cummings J, Duda JE, Lippa C, Perry EK, Aarsland D, Arai H, Ballard CG, Boeve B, Burn DJ, Costa D, Del Ser T, Dubois B, Galasko D, Gauthier S, Goetz CG, Gomez-Tortosa E, Halliday G, Hansen LA, Hardy J, Iwatsubo T, Kalaria RN, Kaufer D, Kenny RA, Korczyn A, Kosaka K, Lee VM, Lees A, Litvan I, Londos E, Lopez OL, Minoshima S, Mizuno Y, Molina JA, Mukaetova-Ladinska EB, Pasquier F, Perry RH, Schulz JB, Trojanowski JQ, Yamada M: Diagnosis and management of dementia with Lewy bodies: third report of the DLB Consortium. Neurology 2005;65:1863-1872. 
Salem et al.: Inadequate Diagnostic Evaluation in Young Patients Registered with a

Diagnosis of Dementia: A Nationwide Register-Based Study

14 McKhann G, Drachman D, Folstein M, Katzman R, Price D, Stadlan EM: Clinical diagnosis of Alzheimer's disease: report of the NINCDS-ADRDA Work Group under the auspices of Department of Health and Human Services Task Force on Alzheimer's Disease. Neurology 1984;34:939-944.

15 McKhann GM, Albert MS, Grossman M, Miller B, Dickson D, Trojanowski JQ: Clinical and pathological diagnosis of frontotemporal dementia: report of the Work Group on Frontotemporal Dementia and Pick's Disease. Arch Neurol 2001;58:1803-1809.

16 Waldemar G, Dubois B, Emre M, Georges J, McKeith IG, Rossor M, Scheltens P, Tariska P, Winblad B: Recommendations for the diagnosis and management of Alzheimer's disease and other disorders associated with dementia: EFNS guideline. Eur J Neurol 2007;14:e1-e26.

17 Phung TK, Andersen BB, Kessing LV, Mortensen PB, Waldemar G: Diagnostic evaluation of dementia in the secondary health care sector. Dement Geriatr Cogn Disord 2009;27:534-542.

18 World Health Organization: The ICD-10 Classification of Mental and Behavioral Disorders: Diagnostic Criteria for Research. Geneva, World Health Organization, 1993.

19 Sorbi S, Hort J, Erkinjuntti T, Fladby T, Gainotti G, Gurvit H, Nacmias B, Pasquier F, Popescu BO, Rektorova I, Religa D, Rusina R, Rossor M, Schmidt R, Stefanova E, Warren JD, Scheltens P: EFNS-ENS Guidelines on the diagnosis and management of disorders associated with dementia. Eur J Neurol 2012;19:1159-1179.

-20 Hort J, O’Brien JT, Gainotti G, Pirttila T, Popescu BO, Rektorova I, Sorbi S, Scheltens P: EFNS guidelines for the diagnosis and management of Alzheimer's disease. Eur J Neurol 2010;17:1236-1248.

-21 Rossor M, Collinge J, Fox N, Howard R, Mallucci G, Mummery C, Warren J: Cognitive impairment and dementia; in Clarke C, Howard R, Rossor M, Shorvon S (eds): Neurology: A Queen Square Textbook. Oxford, Blackwell Publishing Ltd, 2009, pp 245-288.

-22 Rogers BS, Lippa CF: A clinical approach to early-onset inheritable dementia. Am J Alzheimers Dis Other Demen 2012;27:154-161.

23 Kelley BJ, Boeve BF, Josephs KA: Cognitive and noncognitive neurological features of young-onset dementia. Dement Geriatr Cogn Disord 2009;27:564-571.

24 McMurtray A, Clark DG, Christine D, Mendez MF: Early-onset dementia: frequency and causes compared to late-onset dementia. Dement Geriatr Cogn Disord 2006;21:59-64.

25 Picard C, Pasquier F, Martinaud O, Hannequin D, Godefroy O: Early onset dementia: characteristics in a large cohort from academic memory clinics. Alzheimer Dis Assoc Disord 2011;25:203-205.

26 Shinagawa S, Ikeda M, Toyota Y, Matsumoto T, Matsumoto N, Mori T, Ishikawa T, Fukuhara R, Komori K, Hokoishi K, Tanabe H: Frequency and clinical characteristics of early-onset dementia in consecutive patients in a memory clinic. Dement Geriatr Cogn Disord 2007;24:42-47.

27 Draper B, Karmel R, Gibson D, Peut A, Anderson P: Alcohol-related cognitive impairment in New South Wales hospital patients aged 50 years and over. Aust NZ J Psychiatry 2011;45:985-992.

28 Oslin D, Atkinson RM, Smith DM, Hendrie H: Alcohol related dementia: proposed clinical criteria. Int J Geriatr Psychiatry 1998;13:203-212. 